\title{
Оценка качества экономического пространства регионов Европейского Севера России ${ }^{1}$
}

\section{Ирина Секушина}

Вологодский научный центр Российской академии наук, г.Вологда, Россия

\author{
Информация о статье \\ Поступила в редакиию: \\ 06.11 .2020 \\ Принята \\ к опубликованию: \\ 14.12.2020 \\ УДК 338.984 \\ JEL R12
}

\section{Ключевые слова:}

экономическое пространство, оценка качества экономического пространства, Европейский Север России, регион

\section{Keywords: \\ economic space, assessing the economic space quality, Euro- pean North of Russia, region}

\begin{abstract}
Аннотация
В статье разрабатываются теоретико-методические положения оченки качества экономического пространства. Представлена авторская методика оценки качества экономического пространства, проведена ее апробация на примере регионов Европейского Севера России. В результате исследования установлено, что качество экономического пространства рассмотренных субъектов РФ имеет как ряд общих характеристик, так и некоторые отличия по показателям плотности населения, размещения экономической деятельности, а также по индикаторам связанности пространства и экономического развития территорий.
\end{abstract}

\section{Assessing the Quality of the Russia's European North Economic Space}

Irina Sekushina

\section{Abstract}

The paper describes the approaches of the contemporary authors to assessing the quality of the regions economic space. The author's method for assessing the economic space quality by five blocks of indicators is presented in the paper: indicators of population density and economic activity; indicators of population distribution and economic activity; indicators of the territory economic development; indicators of connectivity and the level of transport infrastructure development; indicators of the level and quality of the population life. This method was tested by the example of the European North of Russia regions. The regions were ranked based on the rating, and the total rating for each block was compiled based on the sum of points. The Vologda oblast is the leader in the context of the population density and economic activity, it has the highest scores on all points except for the economic activity density indicator. In terms of population distribution and economic activity three regions scored the same number of points: the republics of Karelia and Komi, as well as the Vologda oblast. The leader of the rating in the sense of the territories economic development is the Murmansk region, which has the best results in the matter of investments in fixed assets and paid services. From the viewpoint of connectivity and the level of transport communication, the highest quality of economic space is in the Vologda region, and the lowest one is in the Republic of Komi. As regards the level and quality of the population life,

\footnotetext{
${ }^{1}$ Статья подготовлена в соответствии с государственным заданием для ФГБУН ВолНЦ РАН по теме НИР № 0168-2019-0004 «Совершенствование механизмов развития и эффективного использования потенциала социально-экономических систем».
}

DOI: https://dx.doi.org/10.24866/2311-2271/2020-4/38-50 
the Murmansk region tops the list, and the Republic of Karelia closes the rating. The results of the study can be useful for public authorities in finding and identifying effective methods and tools to create a highquality economic space.

\section{Введение}

Проведенные в 1990-е годы в российской экономике рыночные реформы оказали значительное влияние на трансформацию экономического пространства страны. С переходом к рынку увеличилась асимметричность развития регионов, интенсивность межрегиональных взаимодействий была значительно ослаблена в результате разрыва связей между экономическими агентами по поставкам сырья, материалов, готовой продукции, действовавших в плановой экономике. Большая часть предприятий была вынуждена сменить географию рынков сбыта и рынков снабжения, переориентироваться на локальные ресурсы и местных потребителей продукции [1].

Особенно болезненно произошедшие трансформационные процессы перехода к рынку сказались на социально-экономическом развитии северных регионов страны, характеризующихся и без того очаговым характером расселения и размещения производства. Вместе с тем субъекты Европейского Севера России обладают значительным природно-ресурсным и геоэкономическим потенциалом, эффективное использование которого на основе интеграции северных территорий в единое экономическое пространство страны создаст объективные предпосылки для устойчивого развития не только Севера, но и всей страны [2]. В данном контексте особую актуальность представляют вопросы оценки качества экономического пространства. Целью данной статьи является обоснование теоретических положений и разработка методики оценки качества экономического пространства субъектов Российской Федерации. Для реализации поставленной цели были решены следующие задачи: 1) проанализированы существующие теоретикометодологические подходы к определению критериев и показателей оценки качества экономического пространства; 2) разработана и апробирована на материалах Европейского Севера России авторская методика оценки качества экономического пространства; 3) выявлены сильные и слабые стороны сформировавшегося в рассмотренных регионах экономического пространства.

Объектом исследования является экономическое пространство регионов Европейского Севера России, предметом - критерии и показатели оценки его качества. Теоретико-методологическую основу исследования составили труды отечественных и зарубежных ученых по вопросам развития экономического пространства. Информационной базой послужили официальные данные российской статистики, в ходе исследования были использованы методы монографический, сравнительного анализа и синтеза, экономического и статистического анализа.

\section{Теоретико-методологические основы исследования}

В настоящее время экономическое пространство является объектом исследований многих отечественных и зарубежных авторов [3-8]. Среди основных концепций и моделей организации экономического пространства можно выделить модели оптимального размещения в пространстве или штандортные теории (И.Г. фон Тюнен, Г. Хоттелинг, В. Лаунхардт, А. Вебер, А. Леш); концепции «центр-периферия» (В. Кристаллер, Г. Мюрдаль, Дж. Фридман, Т. Хэгерстранд); концепции «полюсов роста» (Ф. Перру, Ж. Будвиль, П. Потье); теории промышленных и экономических районов (А. Маршалл, М. Портер), исследования представителей школы новой экономической географии (П. Кругман, М. Фуджита, Э Венаблса). В числе отечественных исследователей стоит выде- 
лить работы представителей советской школы региональной и пространственной экономики: Н.Н. Колосовского, Г.М. Кржижановского, И.Г. Александрова, Н.Н. Баранского, Н.Н. Некрасова, В.С. Немчинова, А.Г. Гранберга, А.Г. Аганбегяна. Повышенный интерес к изучению пространственной компоненты экономического развития во многом обусловлен тем, что пространственные диспропорции выступают фактором торможения социального и экономического прогресса, замедления темпов роста качества жизни населения [9].

В современной экономической науке существует несколько подходов к определению понятия «экономическое пространство»: территориальный, процессный, ресурсный, информационный, управленческий, институциональный и т.д. [10]. В данном исследовании за основу был взят подход Р.Ф. Гатауллина, А.Г. Каримова, А.Г. Комарова, которые определяли экономическое пространство как «субъективно сконструированную в ходе воспроизводства часть физического пространства, отражающую территориально обособленный и локализованный во времени процесс трансакций между экономическими агентами, формируемый на основе реализации их экономических интересов» [11].

На этапе постиндустриального развития общества все большее значение приобретает изучение вопросов качества экономического пространства как набора показателей характеризующих его с различных сторон. Как справедливо отмечает Н.Д. Родионова «в контексте проблематики развития региональных инновационных систем качество экономического пространства является одним из определяющих факторов, обеспечивающих условия для взаимодействия субъектов инновационной деятельности» [12]. Принимая это во внимание, особый научный интерес представляют вопросы методологии оценки качества экономического пространства. Обусловлено это во многом и тем, что для определения ключевых направлений государственной политики формирования и сохранения единого экономического пространства критически важным становится вопрос определения проблемных регионов, имеющих отклонения по тем или иным параметрам.

При всем многообразии характеристик и параметров качества экономического пространства регионов в большинстве современных исследований [10, 13-15] в основе его оценки лежат три главных критерия, предложенных еще академиком А.Г. Гранбергом: плотность, размещение и связанность [16].

Плотность экономического пространства представляет собой степень насыщенности рассматриваемой территории какими-либо хозяйственными объектами в расчете на единицу площади. Большинство исследователей в качестве основных показателей плотности экономического пространства используют плотность населения (или плотность трудоспособного населения), плотность транспортной инфраструктуры, плотность ВРП, рассчитываемая как объем ВРП на единицу площади. В качестве дополнительных показателей можно также выделить показатели, характеризующие ресурсную обеспеченность территории, уровень развития малого и среднего бизнеса, степень социальной обеспеченности населения, плотность хозяйствующих субъектов и т. д.

Размещение как критерий оценки качества экономического пространства включает в себя показатели равномерности (дифференциации, концентрации) распределения населения и экономической деятельности по территории региона. Данные характеристики неразрывно связаны с показателями плотности, поскольку, чем выше плотность, тем меньшее значение имеет размещение, а чем ниже - тем важнее становится концентрировать экономический потенциал и ресурсы в определенных районах. В качестве показателей размещения чаще всего используются коэффициенты распределения населения предприятий и отраслей. 
Связность экономического пространства отражает насколько интенсивно и взаимосвязано протекают экономические процессы между объектами, насколько сильны экономические связи между элементами пространства. В первую очередь связность пространства зависит от развития транспортной инфраструктуры, поскольку процессы экономической деятельности объектов неразрывно связаны с постоянным перемещением ресурсов (сырья, материалов и комплектующих, готовой продукции) между объектами. Не менее важную роль, особенно на современном этапе развития общества, играет информационная инфраструктура. В качестве основных показателей связности экономического пространства в большинстве современных исследований используются грузооборот всех видов транспорта на единицу территории, охват территории сотовой связью и сетью Интернет.

Предложенные критерии оценки качества экономического пространства в том или ином виде используются во многих современных исследованиях, вместе с тем сам перечень показателей и методологический инструментарий отличаются между собой. К примеру, в работе Т.Н. Аврамчиковой [10] предлагается методика оценки качества экономического пространства, учитывающая как количественные, так и качественные социально-экономические показатели. За основу определения качественных значений показателей, по мнению автора, могут быть взяты показатели в экономически развитых западных странах или в других субъектах РФ.

Определенный интерес представляют труды М.Н. Чувашовой [14], где акцент делается на оценке качества экономического пространства ресурсноориентированных регионов. За основу выбраны все те же критерии: плотность, размещение, связанность, однако к ним добавлен новый блок индикаторов, характеризующих экономический потенциал, в том числе сырьевой, а также инфраструктурный комплекс региона и уровень восприятия территории населением и инвесторами. Данный подход позволяет более полно отразить специфику, потенциальные возможности и неиспользуемые резервы экономики регионов сырьевой направленности. Для комплексной оценки качества экономического пространства как региона в целом, так и отдельных его территориальных округов, М.Н. Чувашовой предлагается производить расчет интегрального показателя по выделенным основным направлениям на основе массива данных объективных индикаторов.

В работе М.В. Шмаковой [15] в качестве ключевых выбраны следующие характеристики качества экономического пространства: однородность, связность, плотность, фрактальность и способность к саморазвитию. Главным преимуществом данного подхода, по мнению автора, является возможность учета пространственной компоненты в разработке стратегических документов социально-экономического развития территорий.

А.А. Урунов в своих исследованиях [17] придерживается системного подхода к оценке качества экономического пространства, т.е. рассматривает его как сложную систему, включающую множество других пространств. В качестве показателей оценки качества экономического пространства региона берутся индексы: инвестиций в основной капитал, инвестиций в человеческий капитал, инфляции, бюджетной обеспеченности, уровня занятости населения, ожидаемой продолжительности жизни, качества жизни, средней цены рабочей силы, ВРП на душу населения и др. При этом автором предлагается использовать метод экспертных оценок для определения удельных весов каждого из выбранных показателей. На основе данных среднероссийских показателей рассчитывается эталонное значение - интегральный показатель качества экономического пространства, по которому в дальнейшем производится сравнение регионов России.

В исследованиях Поляковой А.Г. [18] акцентируется внимание на необходимости исследования суммарных и обобщенных представлений населения о качест- 
венных характеристиках социально-экономического пространства региона, ведущих к изменению качества их жизни. Основой авторской методики является проведение анкетного опроса жителей региона и проведение оценки качества социальноэкономического пространства по 4 критериям: благосостояние населения, качество трудовой жизни, качество социальной сферы и безопасность жизнедеятельности.

Рассмотренные нами методики обладают как преимуществами, так и некоторыми недостатками. В некоторых из них предлагается использовать метод экспертных оценок или метод социологического опроса населения, что в определенной степени усложняет процесс проведение оценки качества экономического пространства. С данной точки зрения метод рейтинговых оценок является более простым и доступным к применению.

На основе уже существующих подходов, нами был разработана методика оценки качества экономического пространства регионов. За основу была взята рейтинговая оценка регионов по нескольким показателям, сгруппированным в отдельные блоки, характеризующие качество экономического пространства с разных сторон (табл. 1).

\section{Перечень показателей оценки качества экономического}

Таблица 1 пространства регионов Европейского Севера России

\begin{tabular}{|c|c|}
\hline Блок & Показатели \\
\hline $\begin{array}{l}\text { А. Показатели плот- } \\
\text { ности населения и } \\
\text { экономической дея- } \\
\text { тельности }\end{array}$ & $\begin{array}{l}\text { 1. Общая плотность населения (чел./км²); } \\
\text { 2. Плотность размещения предприятий и организаций (ед./на } 1 \text { жителя региона); } \\
\text { 3. Плотность экономической деятельности (ВРП тыс. руб./на } 1 \text { жителя региона); } \\
\text { 4. Плотность автомобильных дорог общего пользования с твердым покрытием (км/1000 } \\
\text { кв. км.). }\end{array}$ \\
\hline $\begin{array}{l}\text { Б. Показатели разме- } \\
\text { щения населения и } \\
\text { экономической дея- } \\
\text { тельности }\end{array}$ & $\begin{array}{l}\text { 1. Доля населения, проживающего в самом крупном населенном пункте региона (\% от } \\
\text { общей численности населения региона); } \\
\text { 2. Количество населенных пунктов на } 1 \text { тыс. км²; } \\
\text { 3. Отношение максимального и минимального значения инвестиций в основной капи- } \\
\text { тал, осуществляемых организациями, находящимися на территории муниципального } \\
\text { образования субъекта РФ (без субъектов малого предпринимательства), на } 1 \text { человека; } \\
\text { 4. Отношение максимального и минимального значения показателя «Отгружено това- } \\
\text { ров собственного производства, выполнено работ и услуг собственными силами (без } \\
\text { субъектов малого предпринимательства) на территории муниципального образования } \\
\text { субъекта РФ). }\end{array}$ \\
\hline $\begin{array}{c}\text { Г. Показатели связан- } \\
\text { ности и магистрализа- } \\
\text { ции }\end{array}$ & $\begin{array}{l}\text { 1. Оценка уровня развития транспортной инфраструктуры субъекта (коэффициент } \\
\text { Успенского); } \\
\text { 2. Доля населения, использующая сеть Интернет (\% от общей численности населения); } \\
\text { 3. Доля организаций, использующих сеть Интернет (\% от общей численности исследо- } \\
\text { ванных организаций). }\end{array}$ \\
\hline $\begin{array}{c}\text { Д. Показатели уровня } \\
\text { и качества жизни } \\
\text { населения }\end{array}$ & $\begin{array}{l}\text { 1. Отношение средней заработной платы к величине прожиточного минимума (набора } \\
\text { фиксированных товаров), раз; } \\
\text { 2. Уровень безработицы (\%); } \\
\text { 3. Численность населения на } 1 \text { больничную койку (чел.). }\end{array}$ \\
\hline
\end{tabular}

Источник: составлено автором

По каждому показателю производилось ранжирование регионов и присваивались баллы, которые в последствии суммировались по каждому блоку отдельно. Таким образом, получилась многосторонняя оценка, характеризующая различные стороны качества экономического пространства.

\section{Результаты исследования и обсуждение}

При проведении анализа за основу нами были взяты данные официальной статистики за 2018 г. Данные для расчетов и рейтинговые оценки по регионам 
Европейского Севера России представлены в таблице 2. Рассмотрим и проанализируем каждый блок показателей более подробно.

По индикаторам плотности населения и экономической деятельности лидером является Вологодская область, у которой самые высокие рейтинги по следующим показателям: общая плотность населения; плотность размещения предприятий и организаций; плотность автомобильных дорог общего пользования с твердым покрытием. Высокие показатели плотности населения 8,1 чел./км² обусловлены тем, что это самый южный из рассматриваемых регионов с более благоприятными для жизни климатическими условиями. Самый высокий показатель величины валового регионального продукта в расчете на 1 жителя, в Республике Коми: 796,8 тыс. руб./ чел. На втором месте с небольшим отставанием Архангельская область - 712,7 тыс. руб./ чел. По плотности размещения предприятий и организаций, помимо Вологодской области $(33,8$ ед./ тыс. чел.), высокие показатели в Республике Карелия - 33,5 ед. на 1 тыс. жителей. Плотность автомобильных дорог с твердым покрытием в Вологодской области (116 км./1000 км²) значительно выше, показателей в других регионах ЕСР.

В следующем блоке показателей размещения населения и экономической деятельности сразу три региона набрали одинаковое количество баллов: Республики Карелия и Коми, а также Вологодская область. Для более детального анализа рассмотрим показатели в разрезе каждой из составляющих данного блока.

Первым из них является показатель доли населения, проживающего в самом крупном городе региона, что показывает степень концентрации населения в одной точке экономического пространства. Наименьший показатель в Вологодской области: в самом крупном по численности населения городе - Череповце, сосредоточено $27 \%$ жителей региона. Область в своем роде является уникальной, поскольку на ее территории расположено два крупных города: Вологда и Череповец, с сопоставимой численностью населения - 312 и 317 тыс. человек соответственно. Отметим, что данные населенные пункты в ряде научных исследований рассматриваются как ядра формирующейся городской агломерации. В других регионах ЕСР имеется лишь один крупный город с численностью населения свыше 250 тыс. чел. (г. Петрозаводск, г. Сыктывкар, г. Мурманск, г. Архангельск). Подавляющее большинство остальных городов относятся к категории малых и средних, в которых проживает до 100 тыс. чел. Исключением является лишь город Северодвинск Архангельской области с численностью жителей 183,3 тыс. чел. Таким образом, в результате проведенных расчетов на последнем месте рейтинга оказалась Республика Карелия, где более чем $45 \%$ жителей региона проживают в региональном центре - г. Петрозаводске.

По количеству населенных пунктов в расчете на площадь территории безусловным лидером является Вологодская область. В данном регионе показатели превышают аналогичные в других субъектах ЕСР более чем в 8 раз. На последней позиции находится Мурманская область, где на 1 тыс. км² приходится менее чем 1 населенный пункт.

Следующие два показателя данного блока характеризуют степень дифференциации экономической деятельности непосредственно внутри самих регионов. По показателям отношения максимального и минимального значения инвестиций в основной капитал, осуществляемых организациями, находящимися на территории муниципального образования в расчете на 1 человека лидером, причем с достаточно большим отрывом, является Республика Карелия - разрыв в показателях внутри региона составляет 54 раза. Наибольшая дифференциация в минимальных и максимальных показателях объемов инвестиций в Архангельской области - разница составляет 1866 раз. 
Таблийа 2

Показатели оценки качества экономического пространства регионов Европейского Севера России

\begin{tabular}{|c|c|c|c|c|c|c|c|c|c|c|}
\hline Регион & \multicolumn{10}{|c|}{ Показатели оценки качества экономического пространства } \\
\hline \multicolumn{11}{|c|}{ А. Показатели плотности населения и экономической деятельности } \\
\hline & $\begin{array}{l}\text { Общая плотность } \\
\text { населения, чел./км² }\end{array}$ & Рейтинг & $\begin{array}{l}\text { Плотность размеще- } \\
\text { ния предприятий } \\
\text { (ед./на тыс. чел.); }\end{array}$ & Рейтинг & $\begin{array}{c}\text { Плотность эконо- } \\
\text { мической деятель- } \\
\text { ности (ВРП тыс. } \\
\text { руб./ на } 1 \text { жителя); }\end{array}$ & Рейтинг & \begin{tabular}{|c|} 
Плотность автомо- \\
бильных дорог обще- \\
го пользования с \\
твердым покрытием \\
$($ км / тыс. км²) \\
\end{tabular} & Рейтинг & $\begin{array}{c}\text { Общее } \\
\text { количество } \\
\text { баллов }\end{array}$ & $\begin{array}{l}\text { Общий } \\
\text { рейтинг }\end{array}$ \\
\hline Республика Карелия & 3,4 & 3 & 33,5 & 2 & 451,4 & 5 & 48 & 2 & 12 & 3 \\
\hline Республика Коми & 2,0 & 4 & 22,2 & 4 & 796,8 & 1 & 16 & 5 & 14 & 4 \\
\hline $\begin{array}{c}\text { Архангельская область } \\
\text { (+ НАО) }\end{array}$ & 1,9 & 5 & 19,2 & 5 & 712,7 & 2 & 21 & 4 & 16 & 5 \\
\hline Вологодская область & 8,1 & 1 & 33,8 & 1 & 497,0 & 4 & 116 & 1 & 7 & 1 \\
\hline Мурманская область & 5,2 & 2 & 22,9 & 3 & 642,7 & 3 & 23 & 3 & 11 & 2 \\
\hline \multicolumn{11}{|c|}{ Б. Показатели размещения населения и экономической деятельности } \\
\hline & $\begin{array}{c}\text { Доля населения, } \\
\text { проживающего в } \\
\text { самом крупном } \\
\text { населенном пункте } \\
\text { от общей численно- } \\
\text { сти населения (\%) }\end{array}$ & Рейтинг & $\begin{array}{c}\text { Количество насе- } \\
\text { ленных пунктов, ед. } \\
/ \text { тыс. км² }\end{array}$ & Рейтинг & $\begin{array}{c}\text { Соотношение } \\
\text { объемов инвести- } \\
\text { ций в основной } \\
\text { капитал }^{1}\end{array}$ & Рейтинг & $\begin{array}{c}\text { Соотношение объемов } \\
\text { отгруженной продук- } \\
\text { ции }^{2}\end{array}$ & Рейтинг & $\begin{array}{l}\text { Общее } \\
\text { количество } \\
\text { баллов }\end{array}$ & $\begin{array}{l}\text { Общий } \\
\text { рейтинг }\end{array}$ \\
\hline Республика Карелия & 45,2 & 5 & 4,7 & 3 & 54 & 1 & 316 & 1 & 10 & 1 \\
\hline Республика Коми & 29,3 & 2 & 1,8 & 4 & 115 & 2 & 972 & 2 & 10 & 1 \\
\hline $\begin{array}{c}\text { Архангельская область } \\
(+\mathrm{HAO})\end{array}$ & 30,3 & 3 & 6,7 & 2 & 1866 & 5 & 1396 & 4 & 14 & 4 \\
\hline Вологодская область & 27,0 & 1 & 55,6 & 1 & 142 & 3 & 3575 & 5 & 10 & 1 \\
\hline Мурманская область & 39,0 & 4 & 0,9 & 5 & 207 & 4 & 1268 & 3 & 16 & 5 \\
\hline \multicolumn{11}{|c|}{ В. Показатели экономического развития территории } \\
\hline & $\begin{array}{c}\text { Оборот предприятий } \\
\text { и организаций на } \\
\text { душу населения (тыс. } \\
\text { руб./чел.) } \\
\end{array}$ & Рейтинг & $\begin{array}{c}\text { Объем инвестиций в } \\
\text { основной капитал на } \\
\text { душу населения } \\
\text { (тыс. руб./чел.) }\end{array}$ & Рейтинг & $\begin{array}{c}\text { Оборот розничной } \\
\text { торговли на душу } \\
\text { населения (тыс. } \\
\text { руб./чел) }\end{array}$ & Рейтинг & $\begin{array}{c}\text { Объем платных услуг } \\
\text { на душу населения } \\
\text { (тыс. руб./чел) }\end{array}$ & Рейтинг & $\begin{array}{l}\text { Общее } \\
\text { количество } \\
\text { баллов }\end{array}$ & $\begin{array}{l}\text { Общий } \\
\text { рейтинг }\end{array}$ \\
\hline Республика Карелия & 392,2 & 4 & 66468 & 5 & 196389 & 3 & 56538 & 4 & 16 & 4 \\
\hline Республика Коми & 1203,6 & 1 & 151510 & 3 & 184993 & 4 & 59864 & 3 & 11 & 3 \\
\hline $\begin{array}{c}\text { Архангельская область } \\
\text { (+ НАО) }\end{array}$ & 371,0 & 5 & 166425 & 2 & 229576 & 1 & 62005 & 2 & 10 & 2 \\
\hline
\end{tabular}


Окончание таблииы 2

\begin{tabular}{|c|c|c|c|c|c|c|c|c|c|c|c|}
\hline Регион & \multicolumn{11}{|c|}{ Показатели оценки качества экономического пространства } \\
\hline Вологодская область & 950,5 & 2 & \multicolumn{2}{|c|}{127463} & 4 & 159085 & 5 & 49349 & 5 & 16 & 4 \\
\hline Мурманская область & 478,0 & 3 & & & \begin{tabular}{l|l}
1 & \\
\end{tabular} & 225992 & 2 & 79716 & 1 & 7 & 1 \\
\hline \multicolumn{12}{|c|}{ Г. Показатели связанности и магистрализации } \\
\hline & \multicolumn{2}{|c|}{$\begin{array}{c}\text { Оценка уровня развития транс- } \\
\text { портной инфраструктуры } \\
\text { субъекта (коэффициент Успен- } \\
\text { ского) } \\
\end{array}$} & \multicolumn{3}{|c|}{\begin{tabular}{c|c} 
гГ & $\begin{array}{c}\text { Доля населения, исполь- } \\
\text { зующая сеть Интернет от } \\
\text { общей численности насе- } \\
\text { ления, \% }\end{array}$ \\
\end{tabular}} & Рейтинг & \multicolumn{2}{|c|}{$\begin{array}{c}\text { Доля организаций, исполь- } \\
\text { зующих сеть Интернет от } \\
\text { общей численности иссле- } \\
\text { дованных организаций, \% }\end{array}$} & Рейтинг & $\begin{array}{c}\text { Общее } \\
\text { количество } \\
\text { баллов }\end{array}$ & $\begin{array}{l}\text { Общий } \\
\text { рейтинг }\end{array}$ \\
\hline Республика Карелия & \multicolumn{2}{|c|}{0,106} & 2 & \multicolumn{2}{|c|}{82} & 4 & & 93,1 & 2 & 8 & 2 \\
\hline Республика Коми & \multicolumn{2}{|l|}{0,054} & 4 & \multicolumn{2}{|c|}{84,1} & 2 & & 88,3 & 5 & 11 & 5 \\
\hline $\begin{array}{c}\text { Архангельская область } \\
\text { (+ НАО) }\end{array}$ & \multicolumn{2}{|l|}{0,088} & 3 & \multicolumn{2}{|c|}{83,1} & 3 & & 89,7 & 3 & 9 & 3 \\
\hline Вологодская область & \multirow{2}{*}{\multicolumn{2}{|c|}{$\begin{array}{l}0,137 \\
0,029\end{array}$}} & 1 & \multirow{2}{*}{\multicolumn{2}{|c|}{$\begin{array}{l}77,6 \\
887\end{array}$}} & 5 & & 94 & 1 & 7 & 1 \\
\hline Мурманская область & & & 5 & & & 1 & & 89,1 & 4 & 10 & 4 \\
\hline \multicolumn{12}{|c|}{ Д. Показатели уровня и качества жизни населения } \\
\hline & \multicolumn{2}{|c|}{$\begin{array}{c}\text { Отношение средней заработной } \\
\text { платы к величине прожиточно- } \\
\text { го минимума (набора фиксиро- } \\
\text { ванных товаров), раз }\end{array}$} & Рейтинг & \multicolumn{2}{|c|}{ Уровень безработицы (\%) } & Рейтинг & \multicolumn{2}{|c|}{$\begin{array}{l}\text { Численность населения на } \\
1 \text { больничную койку (чел.) }\end{array}$} & Рейтинг & $\begin{array}{c}\text { Общее } \\
\text { количество } \\
\text { баллов }\end{array}$ & $\begin{array}{l}\text { Общий } \\
\text { рейтинг }\end{array}$ \\
\hline Республика Карелия & \multicolumn{2}{|c|}{3,34} & 5 & \multicolumn{2}{|c|}{8,7} & 5 & & 134 & 5 & 15 & 5 \\
\hline Республика Коми & \multicolumn{2}{|l|}{4,11} & 2 & \multicolumn{2}{|c|}{7,3} & 4 & & 100 & 1 & 7 & 2 \\
\hline $\begin{array}{c}\text { Архангельская область } \\
(+\mathrm{HAO})\end{array}$ & \multicolumn{2}{|l|}{3,84} & 3 & \multicolumn{2}{|c|}{6,4} & 2 & & 113 & 3 & 8 & 3 \\
\hline Вологодская область & \multirow{2}{*}{\multicolumn{2}{|c|}{$\begin{array}{l}3,66 \\
4,31\end{array}$}} & 4 & \multicolumn{2}{|c|}{5,1} & 1 & & 130 & 4 & 9 & 4 \\
\hline Мурманская область & & & 1 & & 8 & 3 & & 106 & 2 & 6 & 1 \\
\hline
\end{tabular}


По показателям отношения максимального и минимального значения показателя «Отгружено товаров собственного производства, выполнено работ и услуг собственными силами» также лидером является Республика Карелия. Самый высокий показатель дифференциации в Вологодской области - разрыв между муниципальными образованиями региона более чем в 3575 раз. Последние два показателя свидетельствуют о том, что в Республике Карелия инвестиционная и производственная деятельность размещены относительно равномерно внутри региона, большие перекосы, характерные для других регионов отсутствуют.

Важной составляющей оценки качества экономического пространства являются характеристики экономического развития территорий, где в качестве главных показателей в проведенном исследовании были выбраны оборот предприятий и организаций, объем инвестиций в основной капитал, оборот розничной торговли и объем платных услуг, рассчитанные на душу населения.

Лидером рейтинга по данному блоку является Мурманская область, показавшая лучшие результаты по объемам инвестиций в основной капитал и объемам платных услуг. Последнее место разделили Республика Карелия, занявшая последнее место по объемам инвестиций в основной капитал, и Вологодская область, ставшая антилидером по показателям оборота розничной торговли и объему платных услуг в расчете на душу населения.

Безусловно, в данном блоке необходимо принимать во внимание, тот факт, что все расчеты производятся на душу населения. Соответственно в тех регионах, где численность населения больше, рассчитанные показатели будут меньше. К примеру, в Вологодской области численность жителей более чем в 1,5 раза больше, чем в Мурманской области. В Республике Карелия, напротив численность населения меньше, чем в Мурманской области, в 1,2 раза. Вместе с тем, оба региона находятся на одном месте рейтинга по данному блоку показателей.

Четвертый блок характеризует степень связанности и уровень магистрализации экономического пространства. Для оценки уровня развития транспортной инфраструктуры (железнодорожных путей, автомобильных дорог, водных путей) регионов Европейского Севера России нами был выбран и рассчитан коэффициент Успенского (1):

$$
K_{y}=\frac{L}{\sqrt[3]{S \times H \times t}},
$$

где $\mathrm{K}_{\mathrm{y}}$ - коэффициент Успенского; $L$ - общая длина транспортных путей; S - площадь территории (страны, региона); $H$ - численность населения территории; $t$ - общий вес отправляемых на территории грузов.

Однозначно сложившихся нормативных и пороговых значений данного коэффициента в науке и практике пока не сложилось, но следует отметить, что чем больше его значение, тем выше уровень обеспеченности регионов транспортной инфраструктурой [19]. Согласно проведенным расчетам, лидером рейтинга по уровню развития транспортной инфраструктуры является Вологодская область $\left(\mathrm{k}_{\mathrm{y}}=0,137\right)$, на втором месте - Республика Карелия $\left(\mathrm{k}_{\mathrm{y}}=0,106\right)$. Минимальное значение коэффициента Успенского в Мурманской области $\left(\mathrm{k}_{\mathrm{y}}=0,029\right)$.

В качестве показателей характеризующих связанность нами были взяты доля населения и доля организаций, использующих сеть Интернет. Обусловлено это тем, что в современных условиях ускоренными темпами происходит цифровизация экономики, а одним из главных условий ее инновационного развития становиться повсеместное использование Интернета.

По показателю доли населения, использующего сеть Интернет, лидером является Мурманская область (88,7\%), на последнем месте Вологодская область 
(77,6\%). При этом интересно то, что данный регион занимает первое место по доле организаций, использующих сеть Интернет (94\%). Такая отчасти парадоксальная ситуация объясняется тем, что в Вологодской области достаточно большая часть населения проживает в сельской местности, где нет сети Интернет, в то время как подавляющее число организаций и предприятий расположено в относительно крупных населенных пунктах, где к нему имеется доступ. В целом по сумме показателей по данному блоку наиболее высокое качество экономического пространства в Вологодской области, а низкое - в Республике Коми.

Важной составляющей качества экономического пространства являются показатели уровня и качества жизни населения, что неоднократно отмечалось в работах других исследователей-экономистов $[18,20]$. Первое место по социальным показателям занимает Мурманская область, замыкает рейтинг - Республика Карелия. Одним из показателей данного блока является соотношение средней заработной платы к величине прожиточного минимума (набора фиксированных товаров). Самый высокий результат демонстрирует Мурманская область 4,31 раза, на втором месте с небольшим отставанием Республика Коми - 4,11 раза. Последнее место занимает Республика Карелия, где средняя заработная плата по региону выше прожиточного минимума в 3,34 раза.

По показателям уровня безработицы и численности населения на 1 больничную койку данный регион также находится на последнем месте. Также отметим, что минимальные показатели уровня безработицы в Вологодской области $(5,1 \%)$, в остальных регионах они превышают $6,4 \%$. Численность человек в расчете на 1 больничную койку меньше всего в Республике Коми (100 чел.), немного выше показатели в Мурманской области (106 чел.).

Подводя итог можно сделать следующие выводы о качестве экономического пространства каждого из регионов Европейского Севера России. В Республике Карелии показатели плотности населения и экономической деятельности находятся на среднем по сравнению с другими регионами уровне. При этом положительной характеристикой экономического пространства данного субъекта РФ является достаточно высокая плотность размещения предприятий и организаций (33,5 ед./тыс. чел.). Показатели плотности экономической деятельности или объема ВРП в расчете на душу населения - напротив самые низкие. По показателям размещения населения и экономической деятельности сильной стороной региона является наименьший среди субъектов ЕСР показатель внутрирегиональной дифференциации по объемам инвестиций в основной капитал и объемам отгруженной продукции. Вместе с тем, главная угроза сбалансированному развитию экономического пространства заключается в очень высокой концентрации населения в региональном центре - г. Петрозаводске. Показатели экономического развития территории региона находятся на достаточно низком уровне, в особенности по объему инвестиций в основной капитал в расчете на душу населения. В республике достаточно хорошо развита транспортная инфраструктура, а также высока доля предприятий, использующих сеть Интернет, что говорит о достаточно хорошем уровне магистрализации и связанности экономического пространства региона. Самой слабой и проблемной характеристикой качества экономического пространства региона является социальная сфера. В Карелии самый высокий уровень безработицы и самые низкие показатели соотношения средней заработной платы к величине прожиточного минимума.

Оценки качества экономического пространства Республики Коми также не столь однозначны. Сильной стороной региона являются высокие показатели размещения населения и экономической деятельности. Также данный субъект ЕСР является лидером по показателю плотности экономической деятельности (796,8 тыс. руб. ВРП на 1 жителя). Главной проблемой развития экономическо- 
го пространства региона является низкие показатели связанности и магистрали-

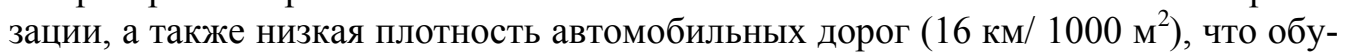
словлено рядом экономико-географических факторов. Социальные показатели находятся на уровне выше среднего, однако проблему представляет высокий уровень безработицы $(7,3 \%)$.

Оценивая качество экономического пространства Архангельской области, можно отметить достаточно высокие показатели экономического развития территории. По объемам инвестиций в основной капитал и объемам платных услуг в расчете на душу населения регион занимает 2 место в рейтинге, а по показателю оборота розничной торговли на душу населения - 1 место. По всем трем показателям, характеризующим степень связанности и уровень магистрализации экономического пространства, регион находится на третьем месте. Самой проблемной стороной в Архангельской области является низкая плотность населения и экономической деятельности. К примеру, общая плотность населения составляет всего 1,9 чел./км², а плотность размещения предприятий - 19,2 ед./тыс. чел.

В Вологодской области напротив самые высокие показатели плотности населения $(8,1$ чел./км²) и размещения предприятий (33,8 ед./тыс.чел). Также в регионе, по сравнению с другими субъектами ЕСР, заметно выше уровень плотности автомобильных дорог (116 км/ тыс. км²). По показателям размещения населения и экономической деятельности регион также один из лидеров. Высокая плотность размещения населенных пунктов (55,6 ед./тыс. км²), свидетельствует об относительно равномерном заселении территории области. Обусловлено это в том числе и тем, что в регионе высокий уровень развития транспортной инфраструктуры - коэффициент Успенского имеет максимальное среди всех субъектов ЕСР значение - 0,137. К слабым сторонам экономического пространства Вологодской области можно отнести низкий уровень показателей уровня и качества жизни населения, а также невысокие показатели экономического развития территории.

В Мурманской области напротив данные показатели достаточно высоки: регион является лидером рейтинга по этим блокам. Показатели плотности населения и экономической деятельности находятся на среднем уровне, а по показателям размещения регион находится на последнем месте. Количество населенных пунктов в расчете на площадь региона составляет всего 0,9 ед./ тыс. км ${ }^{2}$. На достаточно низком уровне находятся и показатели связанности и магистрализации: в регионе самый низкий уровень развития транспортной инфраструктуры (коэффициент Успенского - 0,029), а также один из самых низких показателей доли организаций, использующих сеть Интернет $(89,1 \%)$.

\section{Заключение}

Таким образом, на основе проведенных расчетов можно сделать вывод о том, что регионы Европейского Севера России между собой имеют достаточно большое количество отличий по качеству экономического пространства. В одних регионах высокие показатели плотности населения и экономической деятельности (Вологодская область), в других - показатели экономического развития территорий (Мурманская область), в третьих - показатели размещения населения и экономической деятельности (Республика Карелия, Вологодская область, Республика Коми). При этом выводить общий рейтинг регионов в данном случае представляется, на наш взгляд, не совсем корректным, поскольку анализируемые регионы имеют слишком разные характеристики. Вместе с тем, предложенный методический инструментарий позволяет выявить слабые стороны сформировавшегося в регионах экономического пространства, и уже на основе этих данных определить приоритетные направления его развития. Результаты исследования могут быть полезны органам го- 
сударственной власти в вопросах поиска и определения эффективных методов и инструментов формирования качественного экономического пространства.

\section{Список источников / References}

1. Аджикова А.С., Школьникова Н.Н. Интеграция регионов и качество экономического пространства. Вестник Волгоградского государственного университета. Серия 3. Экономика. Экология. 2016. № 2 (35). cc. 18-26. [Adzhikova A.S., SHkol'nikova N.N. Integraciya regionov i kachestvo ekonomicheskogo prostranstva. [Regional integration and the quality of the economic space.] Vestnik Volgogradskogo gosudarstvennogo universiteta. Seriya 3. Ekonomika. Ekologiya. 2016. № 2 (35). pp. 18-26.]

2. Ускова Т.В., Лукин Е.В., Воронцова Т.В., Смирнова Т.Г. Проблемы экономического роста территории. Вологда: Ин-т социально-экономического развития территорий PAH, 2013. 170 c. [Uskova T.V., Lukin E.V., Voroncova T.V., Smirnova T.G. Problemy ekonomicheskogo rosta territorii [Problems of economic growth of the territory]. Vologda: In-t social'no-ekonomicheskogo razvitiya territorij RAN, 2013. 170 p.]

3. Коломак Е.А. Пространственное развитие России в XXI в. Пространственная экономика. 2019. № 4. cc. 85-106. [Kolomak E.A. Prostranstvennoe razvitie Rossii v XXI v. [Spatial development of Russia in the XXI century] Prostranstvennaya e konomika. 2019. № 4. pp. 85-106.]

4. Минакир П.А., Демьяненко А.Н. Пространственная экономика: эволюция подходов и методология. Пространственная экономика. 2010. № 2. сc. 6-32. [Minakir P.A., Dem'yanenko A.N. Prostranstvennaya ekonomika: evolyuciya podhodov i metodologiya [Spatial economics: evolution of approaches and methodology]. Prostranstvennaya ekonomika. 2010. № 2. pp. 6-32.]

5. Региональная экономика и пространственное развитие: учебник для бакалавриата и магистратуры : в 2-х т / под ред. Л.Э. Лимонова. 2-е изд., перераб. и доп. М.: Юрайт, 2017. T.2. 367 c. [Regional'naya ekonomika i prostranstvennoe razvitie [Regional economy and spatial development]: uchebnik dlya bakalavriata i magistratury : $\mathrm{v} 2$-h t / pod red. L.E. Limonova. 2-e izd., pererab. i dop. M.: YUrajt, 2017. T.2. 367 p.]

6. Krugman P. Complex landscapes in economic geography. American Economic Association. Papers and Proceeding, 1994. no. 84, 413 p.

7. Perru F. Les techniques quantitatives de la piar Economic et societe. Paris: Economic, 1969. 25 p.

8. Fujita, M. Krugman P., Venables A. The Spatial Economy: Cities, Regions and International Trade. The MIT Press, 1999. 367 p.

9. Рохчин В.Е. Основные задачи научного обеспечения пространственного экономического развития регионов (отклик на статью П.А. Минакира и А.Н. Демьяненко «Пространственная экономика: эволюция подходов и методология»). Пространственная экономика. 2010. № 4. cc. 163-167. [Rohchin V.E. Osnovnye zadachi nauchnogo obespecheniya prostranstvennogo ekonomicheskogo razvitiya regionov [Main tasks of scientific support of spatial economic development of regions (response to the article "Spatial economy: evolution of approaches and methodology"By p. A. Minakir and A. N. Demyanenko)] (otklik na stat'yu P.A. Minakira i A.N. Dem'yanenko «Prostranstvennaya ekonomika: evolyuciya podhodov i metodologiya»). Prostranstvennaya ekonomika. 2010. № 4. pp. 163-167.]

10. Аврамчикова Н.Т. Теоретические аспекты оценки качества экономического пространства. Региональная экономика: теория и практика. 2012. № 35 (266). сс. 2-13. [Avramchikova N.T. Teoreticheskie aspekty ocenki kachestva ekonomicheskogo prostranstva [Theoretical aspects of assessing the quality of economic space]. Regional'naya ekonomika: teoriya i praktika. 2012. № 35 (266). pp. 2-13.]

11. Гатауллин Р.Ф., Каримов А.Г., Комаров А.Г. Экономическое пространство: содержание, единство и разрывы. Проблемы современной экономики. 2014. № 4 (52). cc. 196-200. [Gataullin R.F., Karimov A.G., Komarov A.G. Ekonomicheskoe prostranstvo: soderzhanie, edinstvo i razryvy [Economic space: content, unity and gaps]. Problemy sovremennoj ekonomiki. 2014. № 4 (52). pp. 196-200.]

12. Родионова Н.Д. Разработка системы показателей оценки качества экономического пространства региона. Terra Economicus. 2014. Том 12. № 2. cс. 115-119. [Rodionova 
N.D. Razrabotka sistemy pokazatelej ocenki kachestva ekonomicheskogo prostranstva regiona [Development of a system of indicators for assessing the quality of the region's economic space]. Terra Economicus. 2014. Tom 12. № 2. pp. 115-119.]

13. Устинова О.Е. Оценка состояния (качества) экономического пространства во взаимодействии участников инновационного процесса. Инновационное развитие экономики. 2018. № 3(45). 1 часть. сс. 110-117. [Ustinova O.E. Ocenka sostoyaniya (kachestva) e konomicheskogo prostranstva vo vzaimodejstvii uchastnikov innovacionnogo processa [Assessment of the state (quality) of the economic space in the interaction of participants in the innovation process]. Innovacionnoe razvitie e konomiki. 2018. № 3(45). 1 part. pp. 110-117.]

14. Чувашова М.Н. Оценка качества экономического пространства региона сырьевой направленности. Дисс. канд. эконом. наук. Красноярск, 2016. 235 с. [CHuvashova M.N. Ocenka kachestva ekonomicheskogo prostranstva regiona syr'evoj napravlennosti. Diss. kand. ekonom. nauk. [Assessment of the quality of the region's economic space for raw materials. Diss. PhD. (economic)] Krasnoyarsk, 2016. 235 p.]

15. Шмакова М.В. Оценка свойств экономического пространства региона в контексте разработки основных стратегических документов. Азимут научных исследований: экономика и управление. 2020. Т. 9. № 3(32). сc. 410-412. [Shmakova M.V. Ocenka svojstv e'konomicheskogo prostranstva regiona $\mathrm{v}$ kontekste razrabotki osnovny'x strategicheskix dokumentov [Estimate of properties of the economic space of the region in the context of key strategic documents of the development]. Azimut nauchny`x issledovanij: e`konomika $i$ upravlenie. 2020. T. 9. № 3(32). ss. 410-412.]

16. Гранберг А.Г. Основы региональной экономики. М.: ГУВШЭ, 2003. 495 с. [Granberg A.G. Osnovy regional'noj ekonomiki [Fundamentals of the regional economy] M.: GUVSHE, 2003. 495 p.]

17. Урунов А.А., Левина Л.Ф., Остапенко В.А. Качество экономического пространства: проблемы измерения на мезоуровне. Вестник университета. 2020. № 4. сс. 144-151. [Urunov A.A., Levina L.F., Ostapenko V.A. Kachestvo e`konomicheskogo prostranstva: problemy` izmereniya na mezourovne [Quality of economic space: measurement problems at the meso-level]. Vestnik universiteta. 2020. № 4. pp. 144-151.]

18. Полякова А.Г. Регионы нового освоения в условиях модернизации. Тюмень: ИстКонсалтинг, 2010. 232 c. [Polyakova A.G. Regiony novogo osvoeniya v usloviyah modernizacii [Regions of new development in the context of modernization]. Tyumen': IstKonsalting, 2010. 232 p.]

19. Кожевников С.А. Пространственное и территориальное развитие Европейского Севера России: тенденции и приоритеты трансформации. Экономические и социальные перемены: факты, тенденщии, прогноз. 2019. Т. 12. № 6. сc. 91-109. [Kozhevnikov S.A. Prostranstvennoe i territorial'noe razvitie Evropejskogo Severa Rossii: tendencii i prioritety transformacii [Spatial and territorial development of the European North of Russia: trends and priorities of transformation]. Ekonomicheskie i social'nye peremeny: fakty, tendencii, prognoz. 2019. T. 12. № 6. pp. 91-109.]

20. Аничин В.Л., Худобин А.И. Оценка эффективности развития регионального экономического пространства. Инноващии в АПК: проблемы и перспективы. 2020. № 3(27). cc. 135-140. [Anichin V.L., Xudobin A.I. Ocenka e`ffektivnosti razvitiya regional`nogo e'konomicheskogo prostranstva [Assessment of the development efficiency of the regional economic space]. Innovacii v APK: problemy` i perspektivy. 2020. № 3(27). pp. 135-140.]

\section{Сведения об авторе / About author}

Секушина Ирина Анатольевна, младший научный сотрудник, Вологодский научный центр РАН. 160014 Россия, г. Вологда, ул. Горького, д. 56а. ORCID ID 0000-0002-4216-4850.

E-mail: sekushina.isekushina@yandex.ru

Irina A. Sekushina, Junior researcher, Vologda Research Center of the Russian Academy of Sciences. 56A, Gorky Street, Vologda, 160014 Russia. ORCID ID 0000-0002-4216-4850.

E-mail: sekushina.isekushina@yandex.ru 